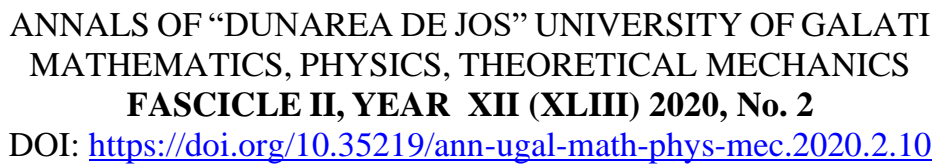

\title{
ATR-FTIR qualitative mineralogical analysis of playground soils from Galati city, SE Romania
}

\author{
Alina Sion ${ }^{1, *}$, Steluta Gosav ${ }^{1}$, Antoaneta Ene $^{1}$ \\ 1 "Dunarea de Jos" University of Galati, Faculty of Sciences and Environment, INPOLDE research center, Re- \\ FORM-UDJG Platform, 800008 Galati, Romania \\ *alina.sion@ugal.ro
}

\begin{abstract}
Soil has an important influence on human health, especially for children, due to more frequent dermal contact, ingestion, and inhalation. Urban playgrounds are of particular concern, because of the presence of a multitude of dust particles of natural or anthropogenic origin, which could enter or interact with the toddlers' body. In this work, the soil samples were collected from important playgrounds from the city of Galati, Romania, being subjected to a mineralogical investigation by Total Attenuated Reflectance Fourier Transform Infrared Spectrometry (ATR-FTIR) technique using a BRUKER TENSOR 27 FTIR spectrometer coupled with a diamond ATR device. Preliminary results of ATR-FTIR analyses of the soil samples highlighted the presence of montmorillonite, kaolinite, quartz, and calcite as soil mineralogical constituents. The main aim of this paper was to observe if the characteristic peak of Chrysotile, a component of asbestos, can be identified in the spectra of the investigated target urban soils from playgrounds.
\end{abstract}

Keywords: soil, FTIR, children health, soil characterization, playground.

\section{INTRODUCTION}

Soil is considered to be the sink of the numerous pollutants released in the environment by many types of natural or anthropic sources [1,2]. Due to the interconnectivity between the environmental components and humans, the soil quality can negatively affect the human state of health, but the most sensitive are the children [3].

In addition to food and drink, children are exposed to trace and toxic elements via many ways, such as ingestion of soil from gardens or playgrounds, indoor and outdoor dust known to its tendency to collect a series of toxic elements, all contaminated by natural or anthropic sources [4].

The soil ingestion by children can occur intentionally, due to the pica tendencies, or unintentionally by physical disturbing of the soil, the lack of hand washing, or the removal of the dirt beneath the fingernails. Usually, if the particle size is thinner than $2 \mathrm{~mm}$ adheres very strongly to the hand and so the ingestion rate is higher [3].

Concerning the impact of the polluted soil on the children's health, the quantity of ingested soil is important, too. The study of Figueiredo et al. (2011) [5] revealed that the daily soil intake for children, was calculated to be between 39-270 mg per day, and for the children that attend day-care centres, was found to be up $90 \mathrm{mg}$ per day. Grouped by age, USEPA (the United States Environmental Protection Agency) concluded that children between the age of 1 and 6 years old may ingest $50 \mathrm{mg}$ per day of soil and if the child has pica tendencies the amount can up to $1000 \mathrm{mg}$ per day [3].

Due to their needs and to sustain a normal physical and mental development, children from the urban areas are spending the time outside, usually in playgrounds, playing and socializing. In this environment, they tend to have significant contact with the soil and dust. The urban soils usually present high concentrations of contaminants such as heavy metals, pesticides, and other harmful 
compounds obtained from various activities. Important sources of soil pollution in urban areas, besides natural occurrence and industrial ones, can be particle deposition due to road traffic, fuel combustion, waste disposal, and corrosion of building materials [4]. The last source of pollution can release important quantities of asbestos [3]. Moreover, the dust existent to a large extent in public playgrounds can represent a hazard for children's health due to the presence of a multitude of natural and anthropogenic particles [6].

Asbestos is formed by a series of natural mineral fibres and is divided into two main groups: serpentine and amphibole. Chrysotile $\left(\mathrm{Mg}_{3}\left(\mathrm{Si}_{2} \mathrm{O}_{5}\right)(\mathrm{OH})_{4}\right)$ is the most widely used and belongs to the serpentine group; from the amphibole group, the most common are Amosite and Crocidolite. Almost $95 \%$ of all produced asbestos is Chrysotile. Due to its physical and chemical properties, it became one of the most important inorganic materials for industrial usage and technological applications. Chrysotile qualities are: acoustic properties, fire-proofing, and decorative purpose. It was used from 1950 up to 1970 as a primary material in the construction of many types of buildings or in isolating many types of sanitary or electric installations. With time, it becomes friable and easily suspended in the air by the wind, but in soil usually occurs from the dumping of asbestos containing waste and during demolition activities [7].

Nowadays, asbestos is considered to be a real hazard for human health because long-term exposure can develop lung cancer, pleural mesothelioma, and many other specific problems at the level of the respiratory system such as asbestosis [8]. Regarding children, they should not be exposed to pollutants during the most delicate phase of their life cycle. Compared to adults, children are more exposed because they breathe with a high frequency and usually on the mouth, spend more time on the floor level where are exposed to dust and fibres and also they often put dirty hands in the mouth [7].

Due to the negative effects on human health, the Environmental Protection Agency (EPA) classifies any material that contains more than $1 \mathrm{wt} \%$ asbestos as asbestos-containing material. These negative effects on the health of humans, developed by the asbestos fibres, led to law regulations for soil pollution in many countries. In Italy for example, the limit concentration must not exceed $1 \mathrm{~g}$ of free fibres for every kilogram of dry soil [8]. In Romania, the asbestos situation is under the Directive 1999/77/CE that bans the use of any type of material that contains asbestos, since 1 January 2005, and the Directive 2003/18/CE forbidden the extraction and production of asbestos products [9].

This paper represents a preliminary study, where was investigated the potential of the Attenuated Total Reflectance Fourier Transform Infrared Spectrometry (ATR-FTIR) technique to characterize the soil mineralogy and to provide a qualitative determination of Chrysotile in soil samples collected from ten popular playgrounds from the city of Galati, SE Romania.

FTIR represents a modern approach for an efficient, fast, and accurate method for soil characterization. Due to the fact that many of the soil analysis are time-consuming and are depending on many protocol steps, the new trend is to use methods for rapid screening (low human error) of a large number of samples. In this category is found to be spectroscopy from near-infrared and midinfrared ranges which, due to the fact that the spectra have specific bands, can be directly associated with organic as well as inorganic functional groups.

Nowadays, FTIR spectroscopy is considered to be a powerful analytical tool for studying in a nondestructive way and with little or no sample preparation, the organic and inorganic compounds of the soil, the soil minerals and humic substances [10], or even providing a forensic soil characterization [11].

\subsection{STUDY AREA}

\section{EXPERIMENTAL}

The soil samples were collected in October 2019, from 10 parks with playgrounds from Galati, Romania. The playgrounds were chosen due to their size and popularity regarding the high number of families with small children that are using them for recreational purposes. In Figure 1 it is presented the location and the geographical coordinates of the chosen parks. 


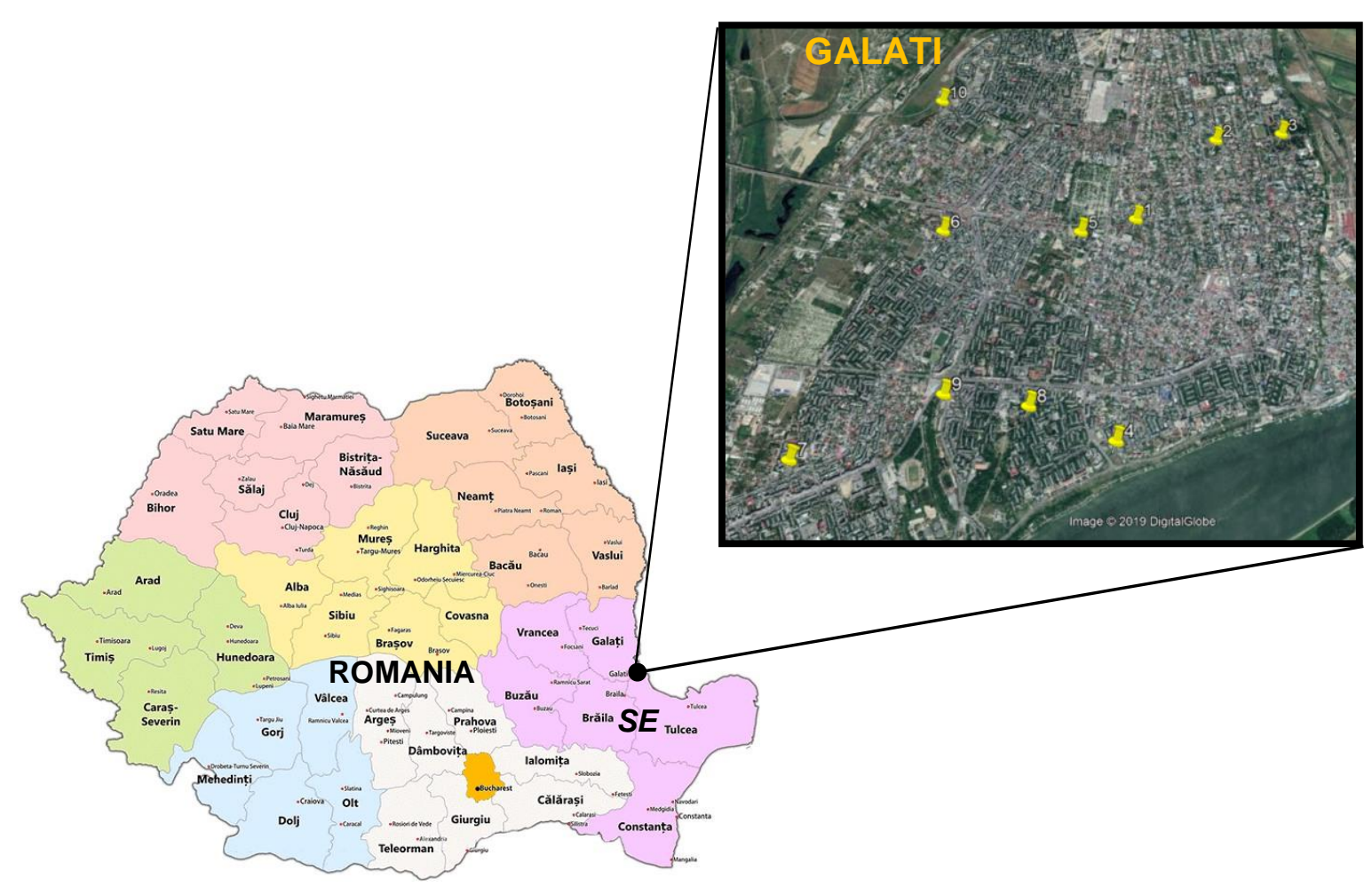

\begin{tabular}{|c|c|c|c|r|}
\hline $\begin{array}{c}\text { Sample } \\
\text { ID }\end{array}$ & Location & North & East & $\begin{array}{c}\text { Altitude } \\
(\mathrm{m})\end{array}$ \\
\hline 1 & Liberty Park & $45^{0} 26^{\prime} 27^{\prime \prime}$ & $28^{0} 02^{\prime} 16^{\prime \prime}$ & 459 \\
\hline 2 & Rizer Park & $45^{0} 26^{\prime} 57^{\prime \prime}$ & $28^{0} 02^{\prime} 38^{\prime \prime}$ & 590 \\
\hline 3 & Public Garden & $45^{0} 27^{\prime} 04^{\prime \prime}$ & $28^{0} 03^{\prime} 08^{\prime \prime}$ & 234 \\
\hline 4 & Viva Park & $45^{0} 25^{\prime} 26^{\prime \prime}$ & $28^{0} 02^{\prime} 32^{\prime \prime}$ & 184 \\
\hline 5 & IFR Park & $45^{0} 26^{\prime} 21^{\prime \prime}$ & $28^{0} 01^{\prime} 57^{\prime \prime}$ & 338 \\
\hline 6 & Siderurgists Park & $45^{0} 26^{\prime} 14^{\prime \prime}$ & $28^{0} 01^{\prime} 08^{\prime \prime}$ & 158 \\
\hline 7 & Micro 17 Park & $45^{0} 25^{\prime} 07^{\prime \prime}$ & $28^{0} 00^{\prime} 43^{\prime \prime}$ & 244 \\
\hline 8 & Children City Park & $45^{0} 25^{\prime} 32^{\prime \prime}$ & $28^{0} 02^{\prime} 56^{\prime \prime}$ & 197 \\
\hline 9 & Closca Park & $45^{0} 25^{\prime} 31^{\prime \prime}$ & $28^{0} 01^{\prime} 27^{\prime \prime}$ & 573 \\
\hline 10 & ANL 13 Park & $4^{0} 26^{\prime} 55^{\prime \prime}$ & $28^{0} 000^{\prime} 50^{\prime \prime}$ & 249 \\
\hline
\end{tabular}

Fig. 1. Sample locations (Google Earth) and geographical coordinates

For soil sampling were used a shovel, plastic bags, and labels. The soil samples were collected from the surface of the soil $(1-2 \mathrm{~cm})$, from the playground sites found in the park. The sample location was established with a GPS phone application. In the laboratory, the samples were air-dried, all the stones and vegetal derbies were removed, and afterward, the soil was grounded and sieved through a $<250 \mu \mathrm{m}$ mesh. The remaining material was labelled and stored for future determination of the soil properties.

\subsection{FTIR ANALYSIS}

Nowadays, Fourier Transform Infrared Spectroscopy (FTIR) is a preferred method that provides fast and accurate information that can be used to characterize the soil's organic and inorganic compounds.

Regarding the FTIR analysis, the small amount of soil sample used in this process can represent in a small percentage the general state of the studied area. This problem can be solved by submitting the soil samples to complementary analysis, or by accomplishing a high number of analyzes on the 
same sample. Because of the limited depth of penetration, perfect contact between the soil sample and crystal is required [12].

The infrared spectra of the soil samples were registered from 4000 to $400 \mathrm{~cm}^{-1}$, at $2 \mathrm{~cm}^{-1}$ resolution by the Attenuated Total Reflectance Fourier Transform Infrared Spectrometry (ATR-FTIR) technique, using a BRUKER TENSOR 27 FTIR spectrometer coupled with a diamond ATR device. This spectrometer belongs to the INPOLDE research center from "Dunarea de Jos" University from Galati, Romania [13,14]. The use of very hard crystals, such as diamond, has an advantage for soil and other solids analysis, due to the fact that dilution with $\mathrm{KBr}$ is no longer necessary. In this way, the analysis becomes non-destructive and allows the sample to be analyzed by other types of methods [10]. The soil samples were placed directly on the crystal, and the soil powder was pressed to achieve an even contact and distribution [13].

\section{RESULTS AND DISCUSSION}

The results of the ATR-FTIR spectroscopic analysis present specific absorption bands that can be attributed to some characteristic functional groups. For all the 10 soil samples, the ATR-FTIR analysis presented similarity in absorption bands, with slightly different intensity values, as seen in Figure 2. The soil samples presented minerals such as: montmorillonite, kaolinite, quartz, and calcite, their characteristic absorption bands are presented in Table 1. Besides the information on the contents of clay groups, non-clay-minerals, organic substances, ATR-FTIR results highlight the presence of Chrysotile $\left(3694 \mathrm{~cm}^{-1}\right)[8]$.

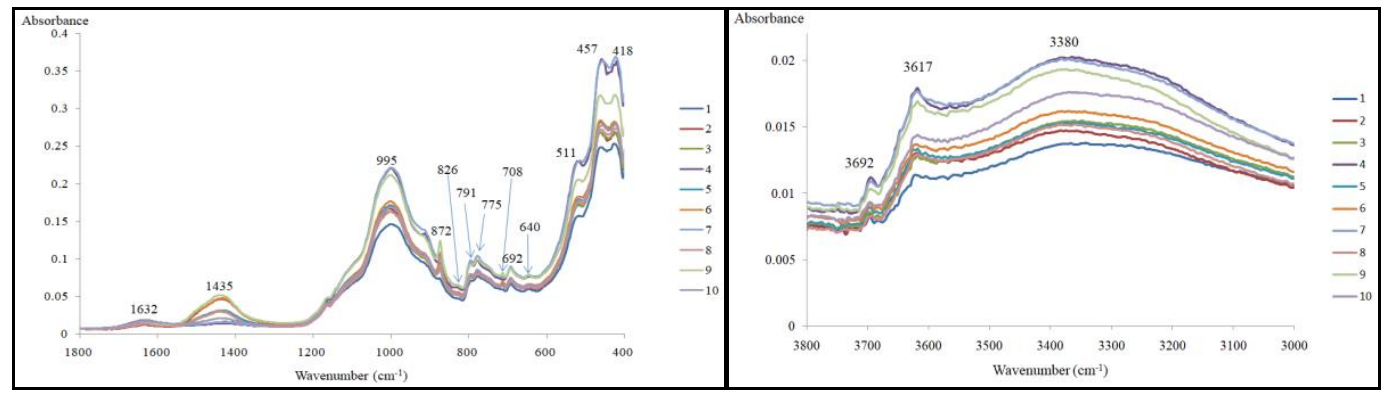

Fig. 2. ATR-FTIR spectra of all the soil samples (wavenumbers from 400 to $1800 \mathrm{~cm}^{-1}$ and from 3000 to $3800 \mathrm{~cm}^{-1}$ )

The authors, Moraru et al. (2019) [14] put in evidence the linear dependence between the intensity of the absorbance band and the concentration of calcite $\left(1435 \mathrm{~cm}^{-1}\right)$ in soils. In our case, high concentrations of calcite can be observed for samples 9,6 , and 2, moderate concentrations for samples 5,8 , and 3 , and very low to nothing for the rest of the samples (Figure 2).

Table 1. Band assignments of ATR-FTIR spectra of soil samples

\begin{tabular}{|c|c|c|}
\hline \multicolumn{2}{|c|}{ Type of mineral (chemical formula) } & $\begin{array}{c}\text { Characteristic } \\
\text { absorption bands }\left(\mathrm{cm}^{-1}\right) \\
{[14]}\end{array}$ \\
\hline \multirow{2}{*}{$\begin{array}{c}\text { Clay } \\
\text { minerals }\end{array}$} & Montmorillonite & $511 ; 826 ; 912 ; 1632 ;$ \\
& $\left((\mathrm{Na}, \mathrm{Ca})_{0.33}(\mathrm{Al}, \mathrm{Mg})_{2}\left(\mathrm{Si}_{4} \mathrm{O}_{10}\right)(\mathrm{OH})_{2} \cdot \mathrm{nH}_{2} \mathrm{O}\right)$ & $3390 ; 3620$ \\
\hline \multirow{2}{*}{$\begin{array}{c}\text { Non-clay } \\
\text { minerals }\end{array}$} & $\mathrm{Kaolinite}\left(\mathrm{Al}_{2} \mathrm{Si}_{2} \mathrm{O}_{5}(\mathrm{OH})_{4}\right)$ & $912 ; 1031 ; 3617 ; 3692$ \\
\cline { 2 - 3 } & Quartz $\left(\mathrm{SiO}_{2}\right)$ & $457 ; 692 ; 775 ; 791 ;$ \\
& & $1110 ; 1168$ \\
\hline
\end{tabular}




\section{CONCLUSIONS}

In this study, using ATR-FTIR soil samples collected from playgrounds from Galati city were analyzed. Besides the study of clay and non-clay minerals, the presence of Chrysotile was also investigated.

The spectrum of the soil samples was very similar in structure to those obtained in previous studies [14]. Generally, ATR-FTIR analysis of the soil sample presented montmorillonite, kaolinite, quartz, and calcite, but Chrysotile did not present any concluded results. In order to complete this research, a future X-Ray Diffraction analysis is needed, also for mineralogical and elemental constituents, and to confirm the presence or absence of Chrysotile in soil samples.

As future directions of this study will be the use of multivariate statistics such as Cluster Analysis (CA) or Principal Component Analysis (PCA) with FTIR data, to obtain quantitative indicators of the composition of the soil components [13].

In conclusion, FTIR spectroscopy represents a useful and low-cost technique in soil quality assessment and monitoring.

Acknowledgements: The authors would like to thank the funding of project BSB27-MONITOX (2018-2021), Joint Operational Programme Black Sea Basin 2014-2020, as well as project no. 71/2020 and grant no. 32/2020 of Joint Institute for Nuclear Research at Dubna. Part of the work was carried out in the frame of sustainability action of Project MIS ETC 1676 (INPOLDE) (2013-2015), Joint Operational Programme Romania-Ukraine-Republic of Moldova 2007-2013.

\section{References}

1. Ene A., Pantelica A., Freitas M.C., Bosneaga, A., EDXRF and INAA analysis of soils in the vicinity of a metallurgical plant. Rom. J. Phys. 56 (2011) 993-1000.

2. Ene A., Bogdevich O., Sion A., Levels of organochlorine pesticides (OCPs) and polycyclic aromatic hydrocarbons (PAHs) in topsoils from SE Romania. Sci. Total Environ. 439 (2012) 76-86.

3. Elom N.I., Dean J.R., Entwistle J.A., How safe is the playground? An environmental health risk assessment of $\mathrm{As}$ and $\mathrm{Pb}$ levels in school playing fields in NE England, Environ Chem Lett 11 (2013) 343-351.

4. Miguel E.D., Chaco E., Mingot, J., Charlesworth S., The relationship between soil geochemistry and the bioaccessibility of trace elements in playground soil, Environ Geochem Health 34 (2012) 677-687.

5. Figueiredo A.M.G., Tocchini M., dos Santos T.F.S., Metals in playground soils of São Paulo city, Brazil , Urban Environmental Pollution 2010, Procedia Environmental Sciences 4 (2011) 303-309.

6. Valido H.I., Padoan E., Moreno T., Querol X., Font O., Amato F., Physico-chemical characterization of playground sand dust, inhalable and bioaccessible fractions, Chemosphere 190 (2018) 454-462.

7. Oomen A.G., Lijzen J.P.A., Relevancy of human exposure via house dust to the contaminants lead and asbestos, RIVM report 711701037/2004 (2004).

8. Foresti E., Gazzano M., Gualtieri, A. F., Lesci, I. G., Lunelli B., Pecchini G., Renna E., N. Roveri, Determination of low levels of free fibres of chrysotile in contaminated soils by X-ray diffraction and FTIR spectroscopy, Anal Bioanal Chem 376 (2003) 653-658.

9. https://ec.europa.eu/taxation customs/dds2/SAMANCTA/RO/Safety/Asbestos RO.htm

10. Artz R.R.E., Chapman S.J., Robertson A.H.J., Potts J.M., Laggoun Défarge, F., et al., FTIR spectroscopy can predict organic matter quality in regenerating cutover peatlands, Soil Biology and Biochemistry 40 (2) (2008) 515-527.

11. Cox R.G., Peterson H.L., Young J., Cusik C., Espinoza E.O., The forensic analysis of soil organic by FTIR, Forensic Science International 108 (2000) 107-116. 
12. Linker R., Soil classification via MID-Infrared spectroscopy, IFIP International Federation for Information Processing, Computer and Computing Technologies in Agriculture, 259(2) (2008) 1137-1146.

13. Gosav S., Ene A., Aflori M., Characterization And Discrimination Of Plant Fossils By ATRFTIR, XRD And Chemometric Methods, Romanian Journal Of Physics 64 (2019) 806.

14. Moraru S.-S., Ene A., Gosav S., Mineralogical Composition Assessment of Soils from, Covurlui and Braila Plains by ATR-FTIR Technique, Proceedings 29 (2019) 80. 